\title{
Influence of Small Amounts of Nickel Addition on Sulfide Stress Cracking Susceptibility in Low Alloy Steel ${ }^{*}$
}

\author{
By Teruo KANEKO** and Akio IKEDA $A^{* * *}$
}

\begin{abstract}
Synopsis
Sulfide stress cracking (SSC) in AISI 4130 type steel containing small amounts of $\mathrm{Ni}$ up to $1 \%$ is investigated. A Shell-bent-beam test shows a significant detrimental effect of $\mathrm{Ni}$, whereas no effect of $\mathrm{Ni}$ is observed in a slow strain rate tensile (SSRT) test.

These results suggest the importance of plastic deformation introduced at the stress-concentrated portion in a Shell type specimen. It is revealed that cold work remarkably deteriorates the SSG resistance of $\mathrm{Ni}$ bearing steel through an acceleration of pitting corrosion, even though its $\mathrm{Ni}$ content is as low as $0.1 \%$.
\end{abstract}

Key words: sulfide stress cracking; nickel addition; low alloy steel.

\section{Introduction}

An application of $\mathrm{Ni}$ bearing steel to the environments containing wet hydrogen sulfide has been avoided because of a probably harmful effect of $\mathrm{Ni}$ on SSC. ${ }^{1-3)}$ According to the standard for alloys used in sour service, $\mathrm{Ni}$ content of any steel is limited to less than $1 \%{ }^{4)}$

Some investigators, however, have reported no effect of $\mathrm{Ni}$ on SSC. ${ }^{5,6)}$ Usually the active path corrosion (APG) mechanism is considered as a dominant factor governing the cracking susceptibility of Ni bearing steel, ${ }^{7)}$ while the other mechanisms involving hydrogen embrittlement are also proposed. ${ }^{8)}$

These discrepancies seem to be caused by insufficient considerations on materials and test methods. In order to make an accurate assessment of $\mathrm{Ni}$ effect, studies should be performed on the materials with similar strength levels and microstructures. As for test methods, it is important to distinguish whether one evaluates the crack initiation characteristic or the propagation.

In this article, the effect of $\mathrm{Ni}$ on $\mathrm{SSC}$ is investigated in $\mathrm{Cr}-\mathrm{Mo}$ steel with fully quenched and tempered microstructure. A Shell-bent-beam test and SSRT test are compared and the role of plastic deformation is examined especially from the viewpoint of an acceleration of the pitting corrosion.

\section{Experimental}

Table 1 shows the chemical compositions of test materials. A small amount of $\mathrm{Ni}$ up to about $1 \%$ is added to AISI 4130 type steel. The steels are melted in a vacuum induction furnace of $20 \mathrm{~kg}$ capacity. The ingots are heated at $1250^{\circ} \mathrm{C}$ and hotrolled to $12 \mathrm{~mm}$ in thickness with finishing temperature above $900^{\circ} \mathrm{C}$. The steel plates are quenched in water after austenitizing at $920^{\circ} \mathrm{C}$ for $1 \mathrm{~h}$ and are finally tempered at $680 \sim 720^{\circ} \mathrm{C}$ for $45 \mathrm{~min}$. Figure 1 shows the shape and dimensions of test specimens.

Shell type specimens are stressed by 3-points-bentbeam method. Two drill holes act as stress raiser. Test is carried out for $200 \mathrm{~h}$ in a $0.5 \%$ acetic acid $\left(\mathrm{CH}_{3} \mathrm{COOH}\right)$ solution, which is saturated with hydrogen sulfide $\left(\mathrm{H}_{2} \mathrm{~S}\right)$ and maintained at $20 \pm 1^{\circ} \mathrm{C}$. A critical stress having a failure probability of $50 \%$ is evaluated as a Sc value.

SSRT test is performed using a tensile machine of maximum loading capacity $5000 \mathrm{~kg}$. Test solution is $5 \%$ sodium chloride $(\mathrm{NaCl})-0.5 \%$ acetic acid $\left(\mathrm{CH}_{3} \mathrm{COOH}\right)$ aqueous solution saturated with $\mathrm{H}_{2} \mathrm{~S}$ and its temperature is controlled within $24 \pm 1^{\circ} \mathrm{C}$. In order to achieve a steady hydrogen distribution, specimens are pre-immersed in the solution for $24 \mathrm{~h}$ without stress. Load is applied at a strain rate of $1 \times 10^{-6}$ $\mathrm{s}^{-1}$. Ductility loss, $I_{L}$, is evaluated as a parameter of degradation in $\mathrm{H}_{2} \mathrm{~S}$ environments, as shown in Fig. 2.

\section{Results and Discussion}

Figure 3 shows the results of the Shell-bent-beam test. It is obvious from the figure that higher the Ni content, lower the critical stress at the same strength level. Although the $S c$ value is the nominal stress evaluated by an elastic bending beam formula, this value can be considered as an allowance of plastic strain for SSG. ${ }^{\text {) }}$ As shown in Fig. 4, sharp pittings are frequently observed on the $\mathrm{Ni}$ bearing steels at the vicinity of drill holes in a specimen. SSC easily

Table 1. Chemical compositions of test materials. (mass\%)

\begin{tabular}{|c|c|c|c|c|c|c|c|c|c|c|}
\hline Steel & C & $\mathrm{Si}$ & Mn & $\mathrm{P}$ & $\mathrm{S}$ & $\mathrm{Ni}$ & $\mathrm{Cr}$ & Mo & $\mathrm{Nb}$ & sol. Al \\
\hline N 1 & 0.28 & 0.30 & 0.49 & 0.003 & 0.005 & $<0.01$ & 0.99 & 0.49 & 0.024 & 0.037 \\
\hline N2 & 0.28 & 0.31 & 0.50 & 0.003 & 0.005 & 0.11 & 1.01 & 0.50 & 0.030 & 0.032 \\
\hline N3 & 0.27 & 0.27 & 0.50 & 0.002 & 0.005 & 0.48 & 0.96 & 0.48 & 0.028 & 0.041 \\
\hline N4 & 0.27 & 0.26 & 0.50 & 0.002 & 0.005 & 1.03 & 0.98 & 0.49 & 0.028 & 0.040 \\
\hline
\end{tabular}

* $\quad$ Presented to the 113th ISIJ Meeting, April 1987, S483, at The University of Tokyo in Tokyo. Manuscript received on December 4, 1987; accepted in the final form on January 14, 1988. C 1988 ISIJ

** Technical Research Laboratories, Sumitomo Metal Industries, Ltd., Nishinagasu-Hondori, Amagasaki 660.

*** Osaka Head Office, Sumitomo Metal Industries, Ltd., Kitahama, Higashi-ku, Osaka 541. 


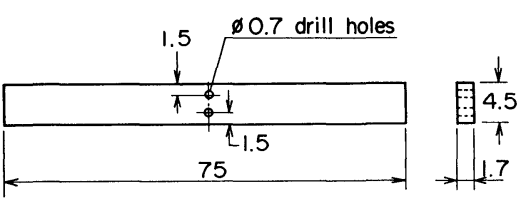

(a) Shell type test specimen

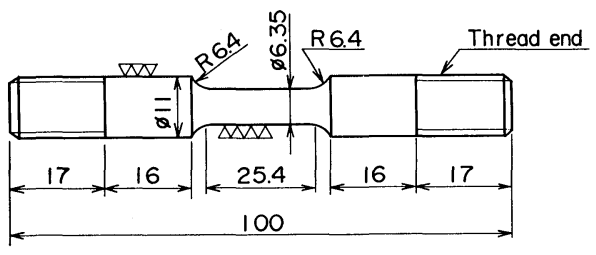

(b) SSRT test specimen

Fig. 1. Shape and dimensions of test specimens. (mm)

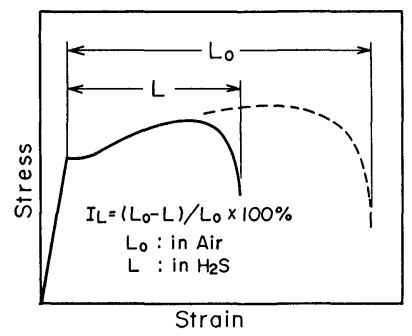

Fig. 2. Evaluation of ductility loss, $I_{L}$, by SSRT test.

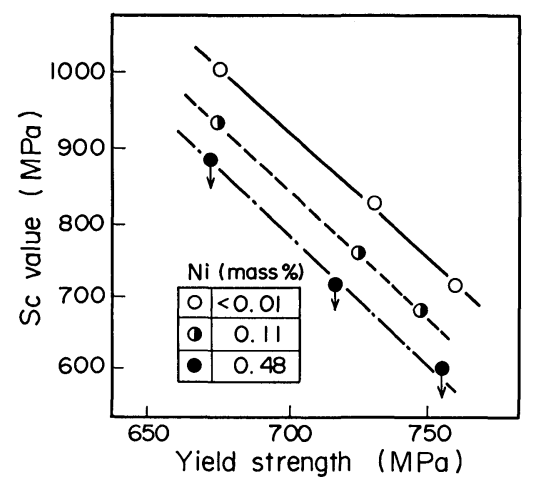

Fig. 3. Effect of Ni content and strength on SSG critical stress by a Shell-bent-beam test.

initiated at the tip of these pittings, ${ }^{7)}$ and this would be a reason why the $\mathrm{SSC}$ resistance of $\mathrm{Ni}$ bearing steel became poor.

On the other hand, no effect of $\mathrm{Ni}$ is observed in SSRT test as shown in Fig. 5. It has been reported that an assessment of ductility loss, $I_{L}$, is very sensitive to metallurgical factors such as strength and microstructure. ${ }^{10)}$ Therefore it could be concluded that the small amounts of $\mathrm{Ni}$ did not affect the microstructure of steel. In fact, the observation of fracture surfaces after SSRT test reveals no difference between $\mathrm{Ni}$ free and Ni bearing steels. Fracture morphology in either case is a transgranular quasi-cleavage type, which is typical for SSG in low alloy steels with relatively low strength.

In order to explain the difference of $\mathrm{Ni}$ effect between the Shell type test and SSRT test, the behavior of pitting corrosion should be taken into ac-

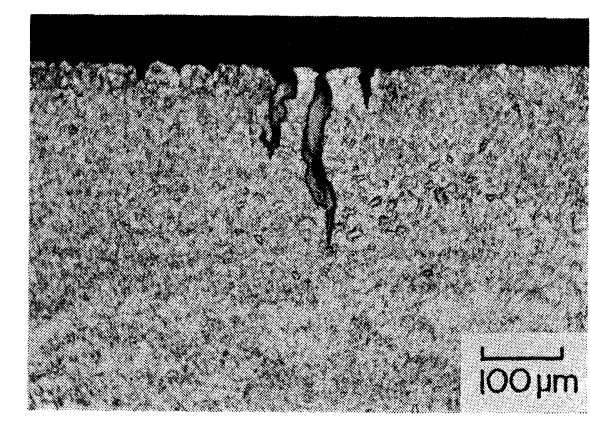

Fig. 4. Example of a sharp pitting observed in a Shell specimen after the test (Steel N2).

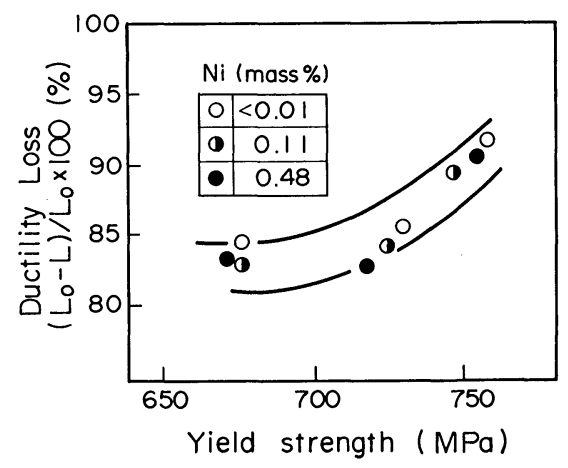

Fig. 5. Effect of Ni content and strength on ductility loss by SSRT test.

count. Generally a relatively long incubation period is required for the formation of pittings, and the test duration of SSRT method seems to be so short to reflect the APG mechanism. In addition, the formation of sharp pittings at the stress concentrated portion in a Shell specimen suggests an important role of the plastic deformation.

Figure 6 shows the effects of $\mathrm{Ni}$ content and cold work on pitting corrosion for materials with yield strength of about $670 \mathrm{MPa}$. It is clearly seen that the pitting formation is significant with increasing $\mathrm{Ni}$ contents and is markedly enhanced by cold work. The lower limit of $\mathrm{Ni}$ content, above which pronounced pittings are observed, is as low as $0.1 \%$ for cold worked materials, while about $0.5 \% \mathrm{Ni}$ is a limit for as tempered steels. Similar results are obtained for materials with higher strength and also for cold reductions ranging from 5 to $20 \%$. The existence of tensile stress is essential and pittings are not formed even in $1 \% \mathrm{Ni}$ steel unless stress is applied.

Figure 7 shows the influence of $\mathrm{Ni}$ content, cold work and applied stress on weight loss by corrosion. In stress free conditions, an increase of $\mathrm{Ni}$ content effectively reduces the corrosion, even though cold work raises its level as a whole. Tensile stress also enhances the corrosion loss and the critical $\mathrm{Ni}$ content, above which the protection effect is eliminated, seems to become lower by the cold work. These data are consistent with the behaviors of pitting corrosion to a certain extent. In order to reveal the influence of metallurgical factors on pitting corrosion, however, more detailed investigations using electrochemical technique are necessary. 
Fig. 6.

Influence of $\mathrm{Ni}$ content and cold work on pitting corrosion by 4 -points-bent-beam test $(80 \%$ of yield stress is applied.).

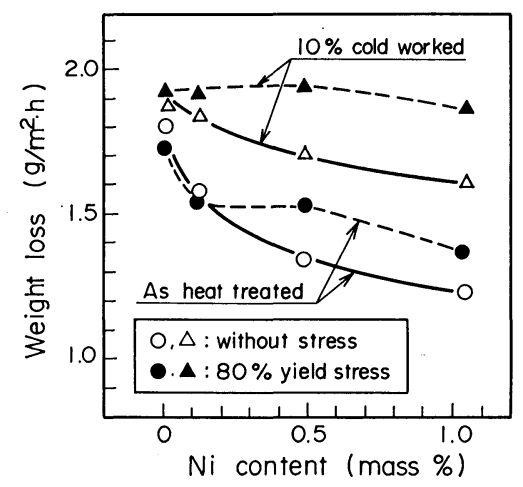

Fig. 7. Influence of $\mathrm{Ni}$ content, cold work and applied stress on weight loss in corrosion.

\section{Conclusions}

(1) Ni effect on SSC susceptibility of low alloy steel depends on test methods. Shell type test shows a significant detrimental effect of $\mathrm{Ni}$, while SSRT test does not. This discrepancy can be explained by considering the effect of plastic deformation on the pit-

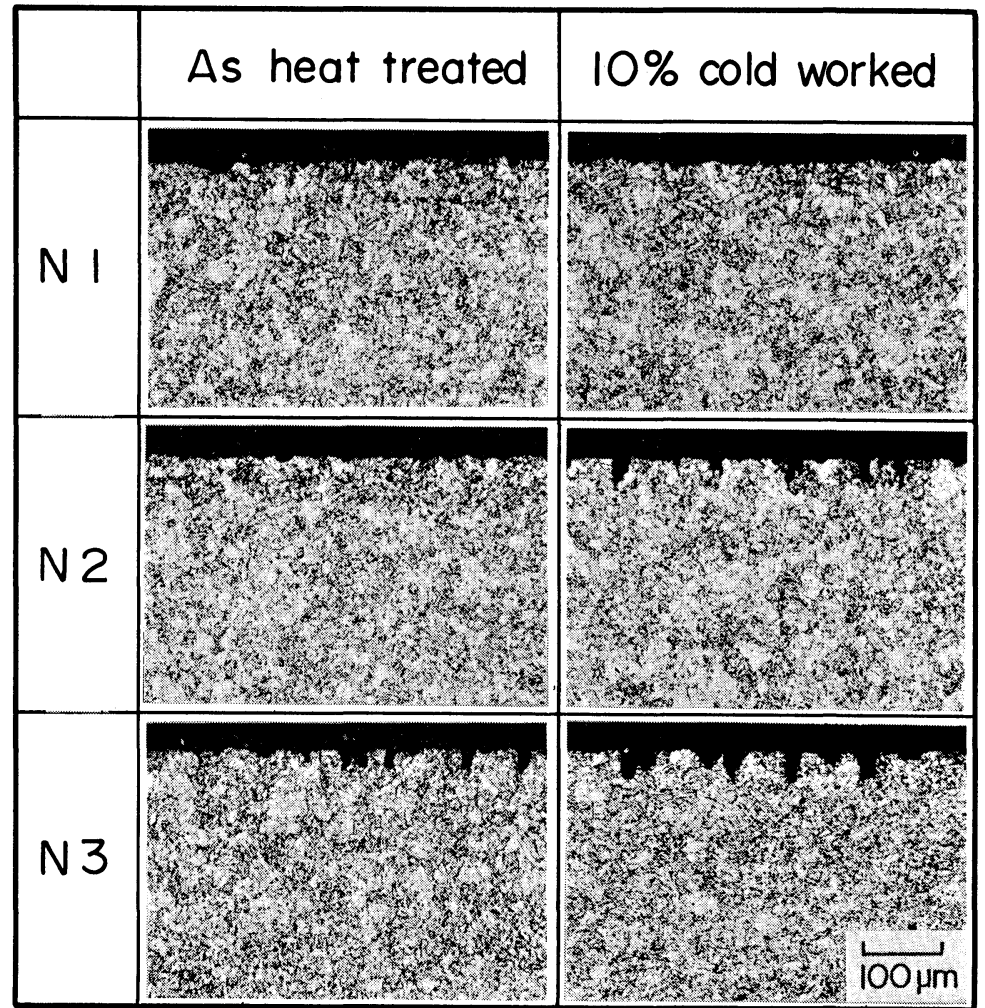

ting corrosion of $\mathrm{Ni}$ bearing steel.

(2) Cold work remarkably accelerates the pitting formation and consequently deteriorates the SSG resistance of $\mathrm{Ni}$ bearing steel, even though its $\mathrm{Ni}$ content is as low as $0.1 \%$.

\section{REFERENGES}

1) J. P. Fraser and G. G. Eldrege: Corrosion, 14 (1958), 44.

2) R. S. Treseder and T. M. Swanson: Corrosion, 24 (1968), 31.

3) M. Kowaka and S. Nagata: 12th Japan Congress on Material Research, Soc. Materials Science, Japan, Kyoto, (1969), 141.

4) National Association of Corrosion Engineers: NACE Standard MR-01-75, (1975).

5) L. W. Vollmer: Corrosion, 8 (1952), 326.

6) E. Snape: Corrosion, 24 (1968), 261.

7) A. K. Dunlop: Corrosion, 34 (1978), 88.

8) A. R. Troiano: Trans. Am. Soc. Met., 52 (1960), 151.

9) J. P. Fraser, G. G. Eldrege and R. S. Treseder: 14th Annual Conference, NAGE, San Francisco, (1958).

10) T. Kaneko, Y. Okada and A. Ikeda: Corrosion/87, NACE, San Francisco, (1987), Paper No. 291. 